\title{
High prevalence of Bordetella pertussis in children under 5 years old hospitalized with acute respiratory infections in Lima, Peru
}

Ivana Pavic-Espinoza, Sandy Bendezú-Medina, Angella Herrera-Alzamora, Pablo Weilg, María J. Pons, Miguel Angel Aguilar-Luis, Verónica Petrozzi-Helasvuo and Juana del Valle Mendoza*

\begin{abstract}
Background: Pertussis diagnosis may go unrecognized when other pathogens, such as respiratory syncytial virus (RSV) circulate.

Methods: A prospective cross-sectional study was conducted in Lima, Peru from January 2009 to September 2010. A total of 596 children under 5 years old admitted with clinical diagnoses of acute respiratory infections were test for B. pertussis and RSV detection by polymerase chain reaction (PCR).

Results: The pertussis toxin and IS481 genes were detected in $19.12 \%(114 / 596)$ of the cases and the respiratory syncytial viruses (RSV-A and RSV-B) were identified in $17.28 \%$ (103/596) of patients. Infants under 3 months old were the most frequently affected by this pathogens in $43 \%(49 / 114)$ and $35.9 \%(37 / 103)$ respectively. An increase of B. pertussis was observed from February to March and from October to November with a Seasonal index between 1.32 and 1.51 and 1.24-3.5 respectively.

Conclusions: Epidemiologic surveillance for B. pertussis is essential in Peru, especially in children that could most benefit from the vaccine. B. pertussis should be suspected in infants hospitalized for acute respiratory symptoms for early treatment and prevent complications.
\end{abstract}

Keywords: Bronchiolitis, Bordetella pertussis, Infants, Vaccine

\section{Background}

Pertussis is an endemic vaccine-preventable disease with the highest morbidity and mortality in the youngest infants [1]. Worldwide, there are an estimated of 16 million cases of pertussis, $95 \%$ of which occur in developing countries, resulting in about 195000 children deaths per year $[1,2]$. In the last years, an increase in reported cases of pertussis has been noted, even in countries with high vaccination coverage [3-6].

Bordetella pertussis is a fastidious gram-negative coccobacillus which causes Pertussis disease, a highly contagious infection of the human respiratory tract also

\footnotetext{
* Correspondence: jdelvall@upc.edu.pe

Centro de Investigación de la Facultad de Ciencias de la Salud. Universidad Peruana de Ciencias Aplicadas - UPC, Av. San Marcos cdra. 2. Cedros de Villa, Lima, Peru

(c) 2015 Pavic-Espinoza et al. Open Access This article is distributed under the terms of the Creative Commons Attribution 4.0 International License (http://creativecommons.org/licenses/by/4.0/), which permits unrestricted use, distribution, and reproduction in any medium, provided you give appropriate credit to the original author(s) and the source, provide a link to the Creative Commons license, and indicate if changes were made. The Creative Commons Public Domain Dedication waiver (http://creativecommons.org/publicdomain/zero/1.0/) applies to the data made available in this article, unless otherwise stated.

known as "whooping cough" $[3,5]$. Pertussis is characterized by three phases: catarrhal, paroxysmal, and convalescent; being the most infectious periods the catarrhal and early paroxysmal phases [7]. This classic presentation is well-known, but is observed less often since the start of immunization [4].

The standard diagnostic criteria for B. pertussis identification and epidemiological surveillance are culture and molecular techniques such as polymerase chain reaction (PCR). The DNA amplification techniques (e.g., PCR) for $B$. pertussis detection are faster, and have increase the sensitivity by approximately $19 \%$ the overall percentage of laboratory-confirmed cases, being the preferred method $[8,9]$. However, in clinical practice the diagnosis is generally reached without microbiological confirmation leading 
to a possible lack of clinical awareness to start early treatment and prevent complications [10].

Pertussis can be especially difficult to diagnose in children under 1 year of age during winter season, when other pathogens, such as respiratory syncytial virus (RSV) or Influenza, are prevalent. In these difficult cases, pertussis acute respiratory symptoms can overlap with those of bronchiolitis or other unspecific acute respiratory infections $[10,11]$. This is especially worrisome in infants too young to be immunized in whom atypical and more severe presentations have been reported, often requiring hospitalization for respiratory or other complications $[7,12,13]$.

In Peru, pertussis is a major health problem that has been raising in the last 5 years [14]. Furthermore, the most affected are infants under 1 year old representing $38 \%$ of cases, despite a national immunization coverage of $92 \%$ in this age group $[15,16]$. Currently, the "whole cell" B. pertussis vaccine (DTwP) is the only available presentation in Peru; and the national coverage level for this vaccination is $88.3 \%$ for the 3 doses of the pentavalent vaccine (DTwP-Hib-HepB) according to the 2014 epidemiology reports [17].

To study the Pertussis epidemiology in Peru is essential in order to understand the real impact of the disease, especially in the most vulnerable population. The aim of this study is to determine the prevalence, epidemiological and clinical characteristics of B. pertussis and Respiratory syncytial virus cases in infants under 5 years old hospitalized with acute respiratory infections in a Peruvian hospital between 2009 and 2010.

\section{Methods}

\section{Patients}

A prospective cross-sectional study was conducted in children under 5 years old admitted to "Hospital Nacional Cayetano Heredia. Lima - Peru" with diagnosis of acute respiratory infection (ARI). A total of 596 patients were studied from January 2009 to September 2010. The study region had a representative population, since Lima is recognized as $B$. pertussis endemic area and has a vaccine coverage similar to the national reports.

Epidemiological and clinical features were registered, including: age, gender and clinical symptoms (fever, rhinorrhea, cough, respiratory distress, malaise, wheezing, pharyngeal congestion, expectoration, vomiting, diarrhea, among others).

This study was approved by the Research Ethics Board of the "Hospital Nacional Cayetano Heredia and Universidad Peruana de Ciencias Aplicadas". Informed written consent was given by the parents or legal guardians of the children before enrolment.

\section{Samples}

Two nasopharyngeal samples were obtained per patient. The first one, by inserting a swab into both nostrils parallel to the palate (calcium alginate swab, USA) and a second swab for the posterior pharyngeal and tonsillar areas (Viral Culture, Becton-Dickinson Microbiology Systems, MD, USA). Both nasal and pharyngeal swabs were placed into the same tube containing viral transport medium (a minimal essential medium buffered with $\mathrm{NaHCO}_{3}$ and supplemented with $2 \%$ fetal bovine serum, penicillin and streptomycin $100 \mathrm{U} / \mathrm{ml}$, amphotericin B $20 \mu \mathrm{g} / \mathrm{ml}$, neomycin $40 \mu \mathrm{g} / \mathrm{ml}$ ). The samples were then stored at $4{ }^{\circ} \mathrm{C}$ until being sent to the Laboratory of molecular biology at "Universidad Peruana de Ciencias Aplicadas (UPC)". On receipt of the samples the swabs were discarded and tubes were centrifuged to pellet the cells, which were re-suspended in $0.8 \mathrm{ml}$ of PBS $1 \mathrm{X}$. Two aliquots of $200 \mu \mathrm{l}$ of each fresh specimen were used for the extraction of nucleic acids and $200 \mu \mathrm{l}$ for bacterial culture.

\section{DNA extraction}

DNA was extracted from a volume of $200 \mu \mathrm{l}$ of each samples using a commercial kit (High Pure Template Preparation Kit, Roche Applied Science, Germany) according to the manufacturer's instructions. DNA extraction was assayed immediately or stored at $-80{ }^{\circ} \mathrm{C}$ until use.

\section{PCR amplification}

The presence of $B$. pertussis was determined using two PCR assays, each specific for an independent region of the B. pertussis genome. A fragment of 191-bp of the pertussis toxin $\mathrm{S} 1$ gene (PTxA) was amplified using the primers PTp1: 5'-CCAACGCGCATGCGTGCAGAxT 'TCGTC-3' and PTp2:5'-CCCTCTGCGTTTTGATG GTGCCTATTTTA- 3' [18]. Meanwhile a 145 bp fragment of the insertion sequence IS481 was amplified using the primers IS481F: 5'-GATTCAATAGGTTGTA TGCATGGTT-3' and IS48R: 5'-TTCAGGCAGACA AACTTGATGGGCG-3' [19]. The described procedures were slightly modified as follows: Fifty $\mu \mathrm{l}$ of reaction mixture containing 25 ul ready mix enzyme (Taq polimerase, $2.5 \mathrm{mM} \mathrm{Mg} \mathrm{Cl} 2 ; 15 \mathrm{mM}$ Tris/HCl PH 8.3, $50 \mathrm{mM} \mathrm{KCl}, 200 \mathrm{uM}$ each deoxynucleotide) (Kappa Biosyste), 20 pmol each primer (Macrogen-Korea), water and $5 \mathrm{ul}$ DNA were amplified using a pre-denaturation of $5 \mathrm{~min}$ at $95{ }^{\circ} \mathrm{C}$, followed by 55 cycles of denaturation for $1 \mathrm{~min}$ at $95{ }^{\circ} \mathrm{C}$, annealing for $1 \mathrm{~min}$ at $55^{\circ} \mathrm{C}$ and elongation for $45 \mathrm{~s}$ at $72{ }^{\circ} \mathrm{C}$, with a final elongation of $10 \mathrm{~min}$ at $72{ }^{\circ} \mathrm{C}$. The presence and size of amplification products were analysed by electrophoresis on $2.5 \%$ gel agarose, containing $3 \mu \mathrm{g} / \mathrm{mL}$ of ethidium bromide, and 
photographed under ultraviolet illumination. The amplified products were sequenced (Macrogen, Seoul, Korea).

Respiratory syncytial virus (RSV-A and RSV-B) were identified by multiplex RT-PCR as previously described by Coiras et. al., [20].

\section{Statistical analysis}

Qualitative variables were reported as frequencies and percentages. All analyses were processed with the IBM Statistical Package for the Social Sciences (SPSS) software version 21.0 (SPSS, Chicago, IL, USA). The chi-square test $\left(x^{2}-\right)$ was used to assess associations between categorical variables while $\mathrm{z}$-Test was used to 30 is significant. A $p$ value $<0.05$ was considered statistically significant. A seasonal index was calculated for Bordetella and Respiratory syncytial virus PCR-confirmed cases from January 2009 to September 2010. Seasonal indexes were calculated dividing the monthly frequency of confirmed cases by the average of cases per year.

\section{Results}

A total of 596 children under 5 years diagnosed with an acute respiratory infection were admitted to the "Hospital Nacional Cayetano Heredia. Lima - Peru” from January 2009 to September 2010. The pertussis toxin and IS481 genes were detected in $19.12 \%(114 / 596)$ of the cases. Respiratory syncytial viruses (RSV-A and RSV-B) were identified in $17.28 \%(103 / 596)$ of patients. Co-infections between $B$. pertussis and RSV-A were observed in 14 patients and only one sample was positive for $B$. pertussis and RSV-B (Table 1).

Positive samples for $B$. pertussis and RSV were analyzed according to age distribution, and infants under
3 months old were the most frequently affected in $43 \%$ $(49 / 114)$ and $35.9 \%(37 / 103)$ respectively. A similar sex distribution was observed in both groups. Moreover, around $59 \%$ of enrolled children had a previous contact with another patient with acute respiratory infections. An equivalent proportion of household contacts was observed for Bordetella pertussis and RSV positive samples (Table 1).

A similar clinical symptoms frequency was observed between patients with $B$. pertussis and RSV. The most common symptoms in both groups were fever, cough, rhinorrhea and respiratory distress, all of them present in more than $60 \%$ of cases. However, among the patients with a positive RSV sample a higher rate of Rhinorrhea $88.35 \%$, Respiratory distress $76.70 \%$ and pharyngeal congestion $33.98 \%$ was observed, in comparison with the Pertussis-positive group (Table 2).

Pneumonia was the most frequent clinical diagnosis in $32.38 \%(193 / 596)$ of the total of patients hospitalized with acute respiratory infections. The diagnosis of Bronchiolitis was more common in children with a positive sample for RSV in $20.39 \%(21 / 103)$. On the contrary, the diagnosis of rhinopharyingitis $6.14 \%(7 / 114)$ was more common in patients with positive $B$. pertussis (Table 3).

A higher prevalence of $B$. pertussis cases were registered between October and November 2009 and February to April 2010. (Figure 1) Seasonal indexes were calculated for $B$. pertussis and RSV positive samples separately. An increase of pcases was observed from February to March and from October to November with a Seasonal index between 1.32 and 1.51 and 1.24-3.5 respectively. A similar predominance was observed in RSV cases from November

Table 1 General characteristics of Bordetella pertussis and Respiratory Syncytial Virus cases

\begin{tabular}{|c|c|c|c|}
\hline \multirow[t]{3}{*}{ Characteristic } & Total ARI $\left.\right|^{a}$ patients & Bordetella pertussis & RSV $^{b}$ \\
\hline & Frequency $(n=596)$ & Frequency $(n=114)$ & Frequency $(n=103)$ \\
\hline & N (\%) & $N(\%)$ & N (\%) \\
\hline \multicolumn{4}{|l|}{ Gender } \\
\hline Female & $243(40.8)$ & $52(45.6)$ & $46(44.7)$ \\
\hline Male & $353(59.2)$ & $62(54.4)$ & $57(55.3)$ \\
\hline \multicolumn{4}{|l|}{ Age } \\
\hline Newborn ( $\leq 28$ days) & $112(18.8)$ & $17(14.9)$ & $11(10.7)$ \\
\hline 29 days $-\leq 3$ months & $121(20.3)$ & $32(28.1)$ & $26(25.2)$ \\
\hline $3-5$ months & $82(13.8)$ & $13(11.4)$ & $11(10.7)$ \\
\hline $6-11$ months & 115(19.3) & $20(17.6)$ & $26(25.2)$ \\
\hline $1-5$ years & $166(27.9)$ & $32(28.1)$ & $29(28.2)$ \\
\hline \multicolumn{4}{|c|}{ Contact with another people with ARI ${ }^{a}$} \\
\hline Yes & $353(59.2)$ & $67(58.8)$ & $59(57.3)$ \\
\hline Not & $243(40.8)$ & $47(41.2)$ & $44(42.7)$ \\
\hline
\end{tabular}

$A R l^{a}$ acute respiratory infection $R S V^{b}$ respiratory syncytial virus 
Table 2 Clinical symptoms observed in patients with positive B. pertussis and RSV by PCR

\begin{tabular}{llll}
\hline Clinical symptoms & Total of patients & Patients positive for Bordetella pertussis & $\begin{array}{l}\text { Patients positive for RSV } \\
\text { Frecuency }(n=103) \\
\text { Frequency }(n=596)\end{array}$ \\
N (\%) & Frequency $(n=114)$ & N (\%) \\
\hline Fever & $596(100)$ & $114(100)$ & $103(100)$ \\
Cough & $448(75.2)$ & $82(71.9)^{a}$ & $92(89.32)^{*}$ \\
Rinorrhea & $448(75.2)$ & $90(78.9)$ & $91(88.35)$ \\
Respiratory distress & $366(61.4)$ & $69(60.5)^{a}$ & $79(76.70)^{*}$ \\
Wheezing respiratory & $230(38.6)$ & $40(35.1)^{a}$ & $59(57.28)^{*}$ \\
Malaise & $150(25.2)$ & $28(24.6)$ & $24(23.30)$ \\
Pharyngeal congestion & $150(25.2)$ & $25(21.9)^{\mathrm{a}}$ & $35(33.98)^{*}$ \\
Expectoration & $142(23.8)$ & $28(24.6)$ & $30(29.13)$ \\
Vomits & $79(13.3)$ & $16(14)$ & $16(15.53)$ \\
Diarrhea & $71(11.9)$ & $13(11.4)$ & $15(14.56)$ \\
Asthenia & $52(8.7)$ & $13(11.4)$ & $9(8.74)$ \\
Conjunctival congestion & $23(3.9)$ & $5(4.4)$ & $5(4.85)$ \\
Abdominal pain & $21(3.5)$ & $2(1.7)$ & $2(1.94)$ \\
Headache & $16(2.7)$ & $3(2.63)$ & $4(3.88)$ \\
Otalgia & $6(1.0)$ & $2(1.75)$ & $1(0.97)$ \\
Myalgia & $6(1.0)$ & $1(1.75)$ & $1(0.97)$
\end{tabular}

* $z$-Test: Patients positive for Bordetella pertussis vs Patients positive for RSV, $p<0.05$

Others ( $<10 \%$ of cases): Ear pain, photophobia, conjunctival congestion, abdominal pain

lymphadenopathy, fatigue, headache, myalgia, skin rash

a 3 children died, one of them in the B.pertussis infection group

to December. However, RSV showed to be also frequent from April to June with a seasonal index between 1.09 and 2.00 (Fig. 2).

\section{Discussion}

Bordetella pertussis is a strict human pathogen which causes whooping cough, an endemic illness responsible of significant morbidity and mortality, especially in infants under 6 months old $[1,2,5]$. Although regional differences exist, Pertussis represents a considerable global disease burden that has been increasing, even in countries with high vaccination coverage $[2,5,13]$. In Peru, an alarming increase of cases has been observed in the last 5 years, and $56 \%$ of cases are reported in infants under 1 year old [12, 14-16]. This have raise especial concern since infants under 6 months old are more vulnerable to disease related complications and carry a higher mortality $[7,21,22]$.

The most common clinical manifestations of B. pertussis infections are prolonged and paroxysmal coughing, accompanied by inspiratory stridor $[1,3]$. However, several factors are known to affect the disease presentation and

Table 3 Clinical diagnosis observed in patients with positive B. pertussis and RSV by PCR

\begin{tabular}{|c|c|c|c|c|c|c|c|c|}
\hline \multirow[t]{3}{*}{ Clinical diagnosis } & \multicolumn{2}{|c|}{ Total of patients } & \multicolumn{3}{|c|}{ Patients positive for Bordetella pertussis } & \multicolumn{3}{|c|}{ Patients positive for $R S V$} \\
\hline & Frequency & Prevalence & Frequency & Prevalence & $p$-value** & Frequency & Prevalence & $p$-value $e^{* *}$ \\
\hline & $(n=596)$ & $(\%)$ & $(n=114)$ & $(\%)$ & & $(n=103)$ & (\%) & \\
\hline Pneumonia & 193 & 32.38 & 30 & $26.32^{*}$ & 0.124 & 44 & $42.72^{*}$ & 0.014 \\
\hline Pharyngitis & 6 & 1.01 & 0 & 0 & 0.231 & 1 & 0.97 & 0.968 \\
\hline Rhinopharyngitis & 33 & 5.54 & 7 & 6.14 & 0.754 & 3 & 2.91 & 0.200 \\
\hline Bronchiolitis & 57 & 9.56 & 9 & $7.9^{*}$ & 0.327 & 21 & $20.39^{*}$ & $<0.05$ \\
\hline Influenza A Infection & 51 & 8.56 & 10 & 8.77 & 0.927 & 6 & 5.83 & 0.276 \\
\hline Whooping cough-like syndrome & 10 & 1.68 & 3 & 2.63 & 0.378 & 2 & 1.94 & 0.819 \\
\hline Obstruction syndrome to bronchiolar & 41 & 6.88 & 9 & 7.89 & 0.634 & 11 & 10.68 & 0.094 \\
\hline
\end{tabular}

* z-Test: Patients positive for Bordetella pertussis vs Patients positive for RSV, $p<0.05$

** $x^{2}$-Test

Others ( $1 \%$ of cases): Sinusitis, respiratory distress syndrome, sepsis late atypical febrile seizure status epilepticus, atypical febrile seizure, gastroenteritis 


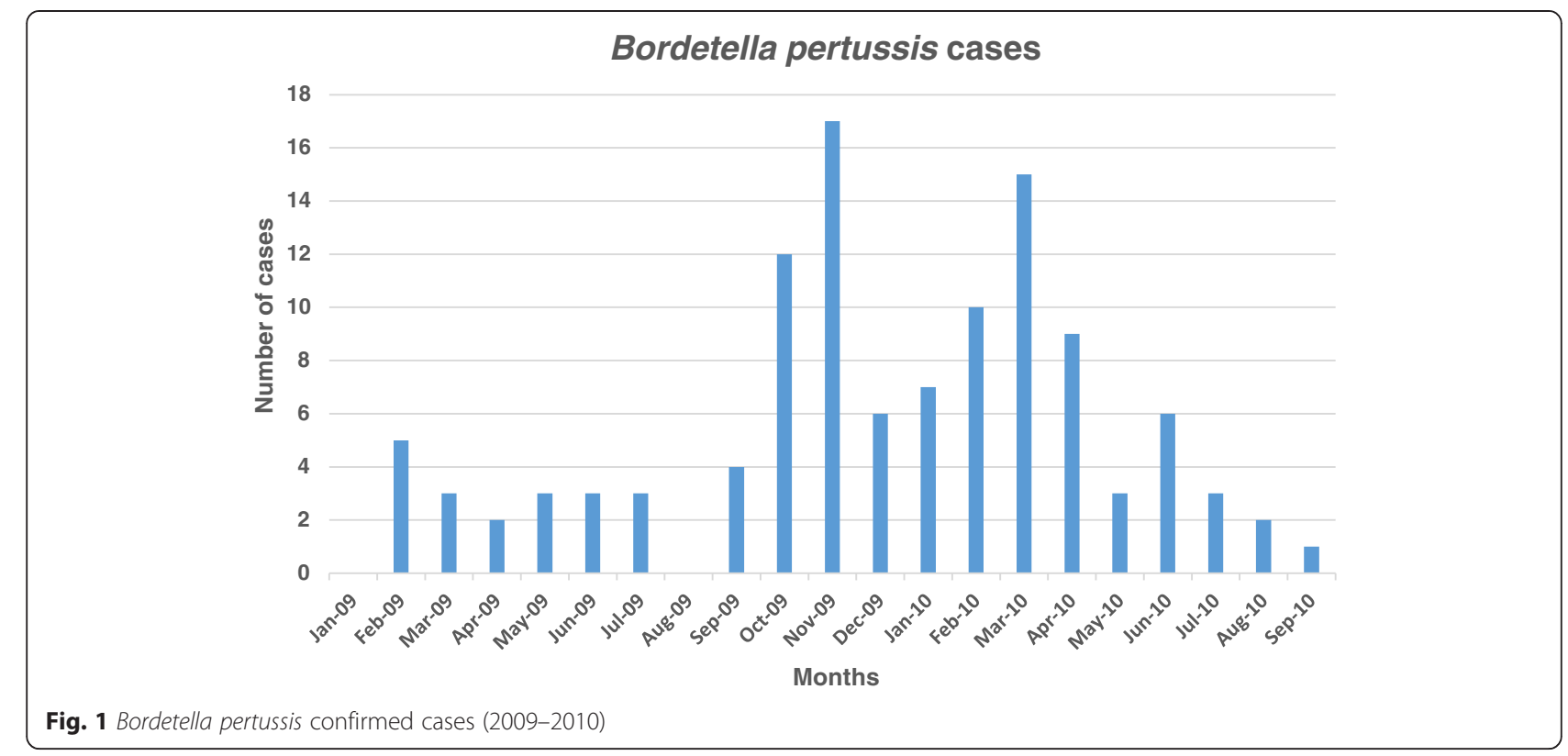

Pertussis diagnosis may go unrecognized when other pathogens, such as respiratory syncytial virus (RSV) or Influenza virus circulate [10, 23, 24]. A retrospective study in Italy, from a group of infants hospitalized from October 2008 to April 2010 for acute respiratory symptoms reported that most of Pertussis cases were infants under 6 months with median of 71.5 days old and a male: female ratio of 6:13 [10]. In our study pertussis toxin and IS481 genes were detected in $19.12 \%(114 / 596)$ of the patients admitted with an acute respiratory infection and infants under 3 months old were the most frequently affected in $43 \%(49 / 114)$ with a similar sex distribution.
Co-infection between Bordetella pertussis and RSV has been previously described to cause severe infections $[10,11]$. A study conducted in a group of infants hospitalized for RSV bronchiolitis showed that almost $2 \%$ of patients were co-infected with $B$. pertussis $[25,26]$. In our series, co-infections were observed in 14 patients between B. pertussis and RSV-A and 1 sample was positive for $B$. pertussis and RSV-B. Moreover, 6 out of 9 cases of coinfections were clinically diagnosed as Bronquiolitis and $B$. pertussis was not suspected at the time of admission. Influenza virus and $B$. pertussis co-infections have been also identified as a possible pathogen present in children

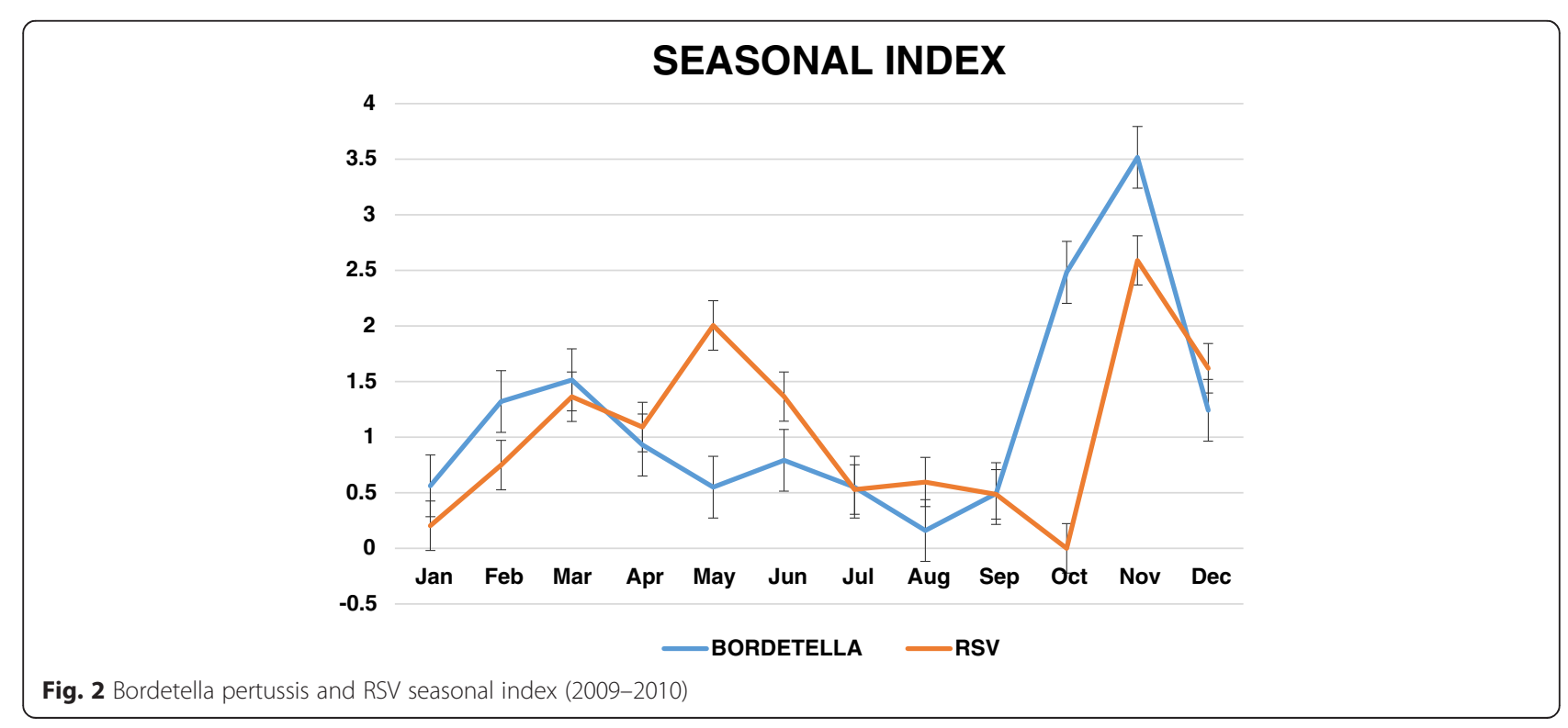


with community-acquired pneumonia; and the pertussis toxin-mediated suppression have been postulate to be responsible to produce more sever presentations [27, 28].

Multiple studies have reported Paroxysmal cough (76.5-91.1 \%), cyanosis (46.7-81.7\%) and respiratory distress $(47.8-55.7 \%)$ as the most common symptoms in children [13, 29, 30]. However, several clinical features might help to suspect the diagnosis of pertussis in infants hospitalized for acute respiratory symptoms. [10]

One study in 2013, compared infants with Pertussis and confirmed RSV bronchiolitis; and the clinical characteristics showed that the percentage of infants with paroxysmal cough was significantly higher in infants with $B$. pertussis. Additionally, cough at admission lasted longer in infants with pertussis than in control infants. Also, fever was significantly lower in infants with pertussis, and more common in patients with bronchiolitis. In our study population, a similar clinical symptoms frequency was observed between patients with $B$. pertussis and RSV. The most frequently reported symptoms were fever, cough, rhinorrhea and respiratory distress, in more than $60 \%$ of cases. However, the presence of rhinorrhea $88.35 \%$, respiratory distress $76.70 \%$ and pharyngeal congestion $33.98 \%$ was more common among patients with RSV. This higher frequency of symptoms in our study may be related to fact that more than $52 \%$ of our patients were hospitalized infants under 6 months old.

The clinical diagnosis of Pertussis in infants can be challenging, especially in children with incomplete immunizations, and some patients may be catalogued as acute viral respiratory infections, before laboratory confirmation. Thus delaying the appropriate antibiotic treatment and isolation measures $[11,24]$. In our series, pneumonia was clearly the most frequent diagnosis in $26.32 \%(30 / 114)$ of the patients with positive B. Pertussis. However, other diagnosis were considered in this group, such as rhinopharingitis, bronchiolitis and influenza infections. In contrast, the diagnosis of Bronchiolitis was more common in $20.37 \%$ (21/103) of children with a positive sample for RSV.

For Bordetella pertussis seasonality, a pattern corresponding to the summer and spring months have been reported in the southern hemisphere [13]. Comparably, a previous study in infants under 6 month of age from 2003 to 2008 in Lima, registered more hospitalizations due to whooping cough during the months of February and September. In our study, a similar distribution was observed with an increase of B. pertussis cases from February to March and from October to November and a Seasonal index between 1.32 and 1.51 and $1.24-3.5$ respectively.

Pertussis represents a considerable disease burden in Peru and the diagnosis is complicated by the limitations of currently available diagnostic tests. Therefore, the only diagnostic tests that are recommended for case confirmation in national reporting are culture and polymerase chain reaction (PCR) $[7,31]$. However, in Peru the use of PCR for surveillance was started recently in 2012 and there is still evidence of a deficient report and registration of cases that limit the analysis of the real disease burden.

\section{Conclusions}

As in other Latin American countries, epidemiologic surveillance for B. pertussis is essential in Peru, especially in children that could most benefit from the vaccine. This study demonstrates a considerable incidence of $B$. pertussis in children previously diagnosed as acute respiratory infections and highlights the importance of possible co-infections that may difficult the diagnosis and prognosis of patients. There is an increasing need for further investigations to better establish the impact of the disease and improve vaccination programs especially in hospitalized children were more severe presentations have been reported.

\section{Competing interests}

On behalf of all authors, the corresponding author states that there are no conflicts of interest or funding related to this study.

\section{Authors' contributions}

IV-E, SB-M and AH-A performed the PCR for Bordetella pertussis and RSV. VP and $\mathrm{JV}$ designed the study protocol; JV was responsible for obtaining funding and laboratory work supervision. PW, MA-L were responsible for the clinical assessment, samples collection and database completion. PW, MJP, VP and JV drafted the manuscript. All authors critically revised the manuscript for intellectual content. All authors read and approved the final manuscript.

\section{Acknowledgements}

This work has been supported partiality the "Concurso Incentivo a la Investigación de la Universidad Peruana de Ciencias Aplicadas" (UPC). LimaPerú

Received: 26 August 2015 Accepted: 24 November 2015

Published online: 02 December 2015

\section{References}

1. Centers for Disease Control and Prevention (CDC) Childhood Whooping Cough Vaccine Protects Most Children For At Least 5 years. Atlanta, Georgia. [Accessed June 18, 2015; Cited on July 13, 2015]. Available at: http://www.cdc.gov/pertussis/surv-reporting.html.

2. World Health Organization (WHO). Immunizations, vaccines and biological: Pertussis. Geneva, Switzerland. [Accessed July 08, 2015; Cited on July 15, 2015]. Available at: http://www.who.int/immunization/topics/pertussis/en/.

3. Torres R, Santos T, Torres R, Pereira W, Fávero LA, Filho OR, et al. Resurgence of pertussis at the age of vaccination: clinical, epidemiological, and molecular aspects. J Pediatr (Rio J). 2015;91(4):333-8.

4. Van den Brink G, Wishaupt J, Douma J, Hartwig NG, Versteegh FG. Bordetella pertussis: an underreported pathogen in pediatric respiratory infections, a prospective cohort study. BMC Infect Dis. 2014;30(14):526.

5. Gao F, Mahoney J, Daly E, Lamothe W, Tullo D, Bean C, Zahraei SM, Parzadeh M. Evaluation of a Multitarget Real-Time PCR Assay for Detection of Bordetella Species during a Pertussis Outbreak in New Hampshire in 2011. J Clin Microbiol. 2014;52(1):302-6.

6. Nikbin V Shahcheraghi LM, Zahraei SM, Parzadeh M Comparison of culture and real-time PCR for detection of Bordetella pertussis isolated from patients in Iran. Iran J Microbiol. 2013;5(3):209-14.

7. Murphy TV, Slade BA, Broder KR, Kretsinger K, Tiwari T, Joyce, et al. Prevention of pertussis, tetanus and diphtheria among pregnant and postpartum women and their infants recommendations of the Advisory 
Committee on Immunization Practices(ACIP). MMWR Recomm Rep. 2008; 57(RR-4):1-51.

8. Hajia M, Rahbar M, Fallah F. Detection of Bordetella pertussis in Infants Suspected to have Whooping Cough. Open Respir Med J. 2012;6:34-6.

9. Riffelmann M, Wirsing von König CH, Caro V, Guiso N; Pertussis PCR Consesus Group. Nucleic Acid amplification tests for diagnosis of Bordetella infections. J Clin Microbiol. 2005;43(10):4925-9.

10. Nicolai A, Nenna R, Stefanelli P, Carannante A, Schiavariello C, Pierangeli A, et al. Bordetella pertussis in infants hospitalized for acute respiratory symptoms remains a concern. BMC Infect Dis. 2013;13:526.

11. Crowcroft N, Booy R, Harrison T, Spicer L, Britto J, Mok Q, et al. Severe and unrecognized: pertussis in UK infants. Arch Dis Child. 2003;88(9):802-6.

12. Perret C, Viviani T, Peña A, Abarca K, Ferrés M. Source of infection in young infants hospitalized with Bordetella pertussis. Rev Med Chile. 2011;139:44854.

13. Gentile A, Romanin V, Juarez Mdel V, Lución MF, Marques MdeL, Mistchenko AS. Epidemiology of Bordetella pertussis in a children's hospital. Arch Argent Pediatr. 2014;112(1):26-32.

14. Red Nacional de Epidemiologia (RENACE). Distribución de Tos Ferina por distritos Peru 2015. [Internet]. Lima, Perú. Dirección General de Epidemiología (DGE). [Accessed on June 12, 2015; Cited on July 09, 2015] Available at: http://www.dge.gob.pe/portal/docs/vigilancia/sala/2015/SE23/ tosf.pdf.

15. Ministerio de Salud del Peru (MINSA).Alerta Epidemiológica: Brote de Tos Ferina en el País. [Internet]. Lima, Peru. Dirección General de Epidemiología (DGE). [Accessed June 12, 2015; Cited on July 13, 2015] Available at: http:// www.inr.gob.pe/transparencia/Epidemiolog\%C3\%ADa/alertas\%20epidemio logicas/ALERTA\%20N\%C2\%BA\%2003\%20BROTE\%20DE\%20TOS\%20FERINA.pdf

16. Ministerio de Salud del Peru (MINSA). Boletín Epidemiológico 06. [Internet] Lima, Peru. Dirección General de Epidemiología (DGE). [Accessed June 22, 2015; Cited on July 10, 2015] Available at: http://www.dge.gob.pe/portal/ docs/vigilancia/boletines/2013/06.pdf

17. Oficina General de Epidemiologia e Informática (OGEI). Ministerio de Salud (MINSA): Boletín. Lima, Peru: Bordetella Pertussis; 2015. Unpublished report.

18. Houard S, Hackel C, Herzog A, Bollen A. Specific identification of Bordetella pertussis by the polymerase chain reaction. Res Microbiol. 1989;140(7):477-87.

19. Glare EM, Paton JC, Premier RR, Lawrence AJ, Nisbet IT. Analysis of a repetitive DNA sequence from Bordetella pertussis and its application to the diagnosis of pertussis using the polymerase chain reaction. J Clin Microbiol. 1990;28(9):1982-7.

20. Coiras M, Pérez-Breña P, García M, Casas I. Simultaneous detection of influenza $A, B$, and $C$ viruses, respiratory syncytial virus, and adenoviruses in clinical samples by multiplex reverse transcription nested-PCR assay. J Med Virol. 2003;69(1):132-44.

21. Tan T, Trindade E, Skowronski D. Epidemiology of Pertussis. Pediatr Infect Dis J. 2005;24(5 Suppl):S10-8.

22. Quian J, Cerisola A, Russomano F, Fernández A, Cappeta M, Uriarte R, et al. Infecciones por Bordetella pertussis en niños menores de un año hospitalizados y sus contactos en el hogar. Arch Pediatr Urug. 2006;77(3): 229-36.

23. Matto S, Cherry J. Molecular Pathogenesis, Epidemiology, and Clinical Manifestations of Respiratory Infections Due to Bordetella pertussis and Other Bordetella Subspecies. Clin Microbiol Rev. 2005;18(2):326-82.

24. Siberry G, Paquette N, Ross T, Perl TM, Valsamakis A. Low prevalence of pertussis among children admitted with respiratory symptoms during respiratory syncytial virus season. Infect Control Hosp Epidemiol. 2006;27(1): 95-7.

25. Walsh P, Overmeyer C, Kimmel L, Feola M, Pusavat J, Nguyen TA. Prevalence of Bordetella pertussis and Bordetella parapertussis in samples submitted for RSV screening. West J Emerg Med. 2008;9:135-40.

26. Walsh PF, Kimmel L, Feola M, Tran T, Lim C, De Salvia L, et al. Prevalence of Bordetella pertussis and Bordetella parapertussis in infants presenting to the emergency department with bronchiolitis. J Emerg Med. 2011;40:256-61.

27. Holter JC, Müller F, Bjoran O, Samdal HH, Marthinsen JB, Jenum PA, et al. Etiology of community-acquired pneumonia and diagnostic yields of microbiological methods: a 3-year prospective study in Norway. BMC Infect Dis. 2015;15:64.

28. Ayala VI, Teijaro JR, Farber DL, Dorsey SG, Carbonetti NH. Bordetella pertussis infection exacerbates influenza virus infection through pertussis toxinmediated suppression of innate immunity. PLoS ONE. 2011;6(4):e19016.
29. Nieto-Guevara J, Luciani K, Montesdeoca-Melian, Mateos Durán M, Estripeaut D. Hospital admissions due to whooping cough: experience of the del niño hospital in Panama. Period 2001-2008. An Pediatr (Barc). 2010; 72(3):172-8.

30. Castillo M, Petrozzi V, Vera M, Reyes I, Bada C, Saénz A. Study Clinical and Epidemiological of Whooping Cough in Breast-Fed Babies under 6 months admitted in three Hospitals of Lima - Peru over the years 2003-2008. Rev Peru Pediatr. 2012;65(1):21-32.

31. Pan American Health Organization (PAHO). Alerta Epidemiológica: Tos Ferina (Coqueluche). [Internet]. Washington, D.C. [Accessed May 22, 2015; Cited on July 11, 2015] Available at: http://www.paho.org/hq/index. php?option=com_docman\&task=doc_view\&gid=19325\&ltemid.

\section{Submit your next manuscript to BioMed Central and we will help you at every step:}

- We accept pre-submission inquiries

- Our selector tool helps you to find the most relevant journal

- We provide round the clock customer support

- Convenient online submission

- Thorough peer review

- Inclusion in PubMed and all major indexing services

- Maximum visibility for your research

Submit your manuscript at www.biomedcentral.com/submit 